Check for updates

Cite this: RSC Adv., 2018, 8, 38499

\title{
Anomalous effect of the aging degree on the ionic permeability of silica shells $\dagger$
}

\author{
Shenghua Wang, ${ }^{a}$ Chaoran Li, ${ }^{a}$ Zhijie Chen, ${ }^{a}$ Zhijie Zhu, ${ }^{a}$ Qishan Zhu, ${ }^{\text {b }}$ Ruijun Tang, ${ }^{b}$ \\ Wei Sun, ${ }^{* c}$ Le He (DD ${ }^{* a}$ and Xiaohong Zhang ${ }^{* a}$ \\ We present a systematic study on the ionic permeability and protective ability of silica shells with different \\ aging degrees by using the acid etching of silica-coated iron oxide nanoparticles as the model reaction. \\ Contradictory to common impressions, we found that the ionic permeability of silica shells increased \\ rather than decreased with the increasing aging degree. This trend may be explained by the chemical \\ nature of the sol-gel silica shell that affects the wettability and, thereby, the transportation of water \\ molecules and hydrated ions. Our study provides novel insights into the protective ability of sol-gel \\ derived silica, which enables us to design thin but low-permeability shells for the stability of inner \\ nanoparticles under harsh conditions without scarifying the performance of core-shell nanostructures.
}

Received 29th October 2018

Accepted 8th November 2018

DOI: $10.1039 / \mathrm{c} 8 \mathrm{ra0} 8936 \mathrm{a}$

rsc.li/rsc-advances

permeability in the core-shell nanostructures for more effective

\section{Introduction}

Owing to their high specific surface areas, nanoparticles exhibit higher chemical reactivity, but lower stability than their bulk counterparts. ${ }^{1-8}$ Increasing the stability of nanoparticles, particularly under harsh conditions, is crucial for their widespread applications in different areas such as catalysis, photonics, environmental remediation, biomedicine, energy conversion and storage. $^{9-17}$ For example, functionalized magnetite-based nanoparticles have been utilized as magnetically recyclable adsorbents for the removal of heavy metal ions from acidic waste water. ${ }^{18-20}$ Nevertheless, they often suffer from the corrosion of iron oxide in acidic environments, leading to the decreased recycling efficiency through magnetic separation and the unwanted loss of adsorbents. In this context, surface coating with a layer of sol-gel silica to construct core-shell structures has been used as a general method to improve the stability of the inner nanoparticles. ${ }^{21-28}$ For example, Tong et al. reported the use of poly(1-vinylimidazole)grafted $\mathrm{Fe}_{3} \mathrm{O}_{4} @ \mathrm{SiO}_{2}$ particles with improved stability as reusable adsorbents for the removal of $\mathrm{Hg}^{2+}$ in waste water. ${ }^{25}$

The protective ability of silica shells depends on their permeability to species that attack the inner nanoparticles. Therefore, it is usually necessary to decrease the shell

${ }^{a}$ Institute of Functional Nano \& Soft Materials (FUNSOM), Jiangsu Key Laboratory for Carbon-Based Functional Materials \& Devices, Soochow University, 199 Ren'ai Road, Suzhou, 215123, Jiangsu, P. R. China.E-mail: lehe@suda.edu.cn; xiaohong_zhang@ suda.edu.cn

${ }^{b}$ Jiangsu Key Laboratory of Thin Films, College of Physics, Optoelectronics and Energy, Soochow University, Suzhou, 215006, Jiangsu, P. R. China

'Department of Chemistry, University of Toronto, 80 St. George Street, Toronto, Ontario, M5S 3H6, Canada. E-mail:wsun@chem.utoronto.ca

$\dagger$ Electronic supplementary information (ESI) available. See DOI: 10.1039/c8ra08936a stabilization under harsh conditions. Conventionally, this requires increasing the thickness of silica shells, which often leads to a decreased level of performance of the inner nanoparticles. ${ }^{29-32}$ For instance, Dravid et al. reported that the magnetic resonance imaging (MRI) performance of $\mathrm{Fe}_{3} \mathrm{O}_{4} @ \mathrm{SiO}_{x}$ particles decreased with the increase of the silica shell thickness. ${ }^{30} \mathrm{Chu}$ et al. found that the photoluminescence of silicacoated lanthanide complexes weakened when increasing the shell thickness. ${ }^{31}$ The use of thick shells also increases the overall particle size and, thus, greatly limits the bio-related applications of silica-coated nanoparticles. ${ }^{16,33-35}$ Therefore, it is of emerging interest to design thin but low-permeability silica shells towards the stabilization of nanoparticles.

Herein we present a systematic study on the protective ability of silica shells with different aging degrees by using the acid etching of silica-coated iron oxide nanoparticles as the model reaction. Our study provides substantial evidences that the permeability of silica shells strongly depends on their aging degrees. Surprisingly we observed that less aged silica shells exhibit lower ionic permeability, and thus better protective ability. This may be explained by the contrast in the wettability between silica shells with different aging degrees. Our study provides novel insights into the protective ability of sol-gel derived silica. This knowledge enables us to design thin but low-permeability shells for the stability of inner nanoparticles under harsh conditions without sacrificing the performance of core-shell nanostructures.

\section{Experimental section}

\subsection{Materials}

All the chemicals were used as received without further purification. Polyvinylpyrrolidone (PVP, $M_{\mathrm{w}}=360000$ ), monosodium 
dihydrogen orthophosphate $\left(\mathrm{NaH}_{2} \mathrm{PO}_{4}\right.$, reagent grade) were obtained from Vetec. Ferric chloride hexahydrate $\left(\mathrm{FeCl}_{3} \cdot 6 \mathrm{H}_{2} \mathrm{O}\right.$, reagent grade) and PSSMA [poly(4-styrenesulfonic acid-comaleic acid) sodium salt] were purchased from Sigma Aldrich. Sodium acetate anhydrous (99\%), ethylene glycol (99.5\%), tetraethyl orthosilicate (TEOS, $>96 \%$ ), ammonium hydroxide solution $\left(\mathrm{NH}_{3} \cdot \mathrm{H}_{2} \mathrm{O}, 28 \mathrm{wt} \%\right)$, ethanol (GR, $\geq 99.8 \%$ ) and hydrochloric acid (36-38\%, analytical reagent) were purchased from Energy chemical, J\&K scientific, TCI, Macklin, Sinopharm Chemical Reagent Co., Ltd and Enox, respectively. Milli-Q water (Millipore, $18.2 \mathrm{M} \Omega \mathrm{cm}$ at $25^{\circ} \mathrm{C}$ ) was used in all experiments.

\subsection{Characterization}

Transmission electron microscopy (TEM) images were obtained with an FEI-Tecnai F20 $(200 \mathrm{kV})$ transmission electron microscope. The particle size distribution of different samples was counted via Nano Measurement (at least 100 particles were included for each sample). Fourier transform infrared (FTIR) spectra were obtained with an FTIR spectrometer (Spectrum One, PerkinElmer) using a standard $\mathrm{KBr}$ pellet technique. The Brunauer-Emmett-Teller (BET) data were collected from a Micromeritics ASAP 2020 HD88. The Fe content of different samples was measured by an inductively coupled plasma source mass spectrometer (ICP-MS) (Aurora M90, Jenoptik). The magnetic properties were measured using a vibrating sample magnetometer (VSM) in the physical property measurement system (PPMS, Quantum Design).

\subsection{Synthesis of $\mathrm{Fe}_{3} \mathrm{O}_{4}$ colloidal nanocrystal clusters (CNCs)}

$\mathrm{Fe}_{3} \mathrm{O}_{4}$ CNCs were synthesized according to a reported recipe. ${ }^{36}$ Under magnetic stirring, $7.5 \mathrm{~g}$ of PSSMA was dissolved in ethylene glycol $(300 \mathrm{~mL})$ to form a clear solution, followed by the addition of $\mathrm{FeCl}_{3} \cdot 6 \mathrm{H}_{2} \mathrm{O}(8.1 \mathrm{~g})$ and sodium acetate $(22.5 \mathrm{~g})$. The obtained homogeneous red brown solution was then sealed in a Teflon-lined stainless-steel autoclave and heated at $200{ }^{\circ} \mathrm{C}$ for 10 hours. When cooled down, the dark precipitates were isolated by a magnet and washed 6 times with Milli-Q water and ethanol alternately, and finally dispersed in ethanol to form a suspension with a concentration of $10 \mathrm{mg} \mathrm{mL}^{-1}$.

\subsection{Synthesis of $\alpha-\mathrm{Fe}_{2} \mathrm{O}_{3}$ ellipsoidal particles}

Ellipsoidal $\alpha-\mathrm{Fe}_{2} \mathrm{O}_{3}$ particles were synthesized according to a reported recipe. ${ }^{37} 1.3 \mathrm{~g}$ of $\mathrm{Fe}_{2} \mathrm{Cl}_{3} \cdot 6 \mathrm{H}_{2} \mathrm{O}, 80 \mu \mathrm{L}$ of $\mathrm{NaH}_{2} \mathrm{PO}_{4}$

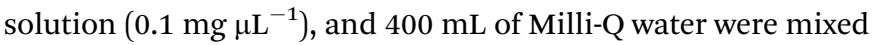
together under sonication. The mixture was then kept in an oven at $100{ }^{\circ} \mathrm{C}$ for 48 hours. The product was collected by centrifugation and washed with Milli-Q water several times, which was finally dispersed in certain amount of Milli-Q water to form a suspension with a concentration of $10 \mathrm{mg} \mathrm{mL.} 5 \mathrm{~mL}$ of the suspension was diluted by $25 \mathrm{~mL}$ of Milli-Q water, followed by the addition of $5 \mathrm{~mL}$ of PVP aqueous solution $\left(M_{\mathrm{w}}: 360000\right.$, $\left.0.04 \mathrm{~g} \mathrm{~mL}^{-1}\right)$. The mixture was then stirred overnight. The PVP modified $\alpha-\mathrm{Fe}_{3} \mathrm{O}_{4}$ particles was collected by centrifugation at $11000 \mathrm{rpm}$ for $30 \mathrm{~min}$. The supernatant was discarded and the precipitate was redispersed in certain amount of ethanol to form a suspension with a concentration of $10 \mathrm{mg} \mathrm{mL}^{-1}$.

\section{5. $\mathrm{SiO}_{2}$ coating}

The $\mathrm{Fe}_{3} \mathrm{O}_{4}$ CNCs and PVP-modified $\alpha-\mathrm{Fe}_{2} \mathrm{O}_{3}$ nanoparticles were then coated with a thin layer of silica via a modified sol-gel method. ${ }^{38}$ Briefly, $20 \mathrm{~mL}$ of the $\mathrm{Fe}_{3} \mathrm{O}_{4} \mathrm{CNCs}$ or $\alpha-\mathrm{Fe}_{2} \mathrm{O}_{3}$ suspension was diluted by $60 \mathrm{~mL}$ of ethanol, followed by the addition of $12 \mathrm{~mL}$ of Milli-Q water. The mixture was then sonicated for 30 minutes. $10 \mathrm{~mL}$ of ammonium hydroxide (28\%) aqueous solution and a certain amount of TEOS $(500 \mu \mathrm{L}$ for CNCs; $700 \mu \mathrm{L}$ for $\alpha-\mathrm{Fe}_{2} \mathrm{O}_{3}$ ) were added into the suspension sequentially. The reaction container was then transferred to a shaking bed, sampled after a certain period. The products were obtained by centrifugation and washed twice with ethanol. Finally, they were dispersed in ethanol with a concentration of $10 \mathrm{mg} \mathrm{mL}^{-1}$.

\subsection{Acid etching}

$5 \mathrm{~mL}$ of the suspension of $\mathrm{Fe}_{3} \mathrm{O}_{4} @ \mathrm{SiO}_{2}$ particles (with different sol-gel reaction times) was centrifuged at $13000 \mathrm{rpm}$ for $6 \mathrm{~min}$. The precipitate was redispersed in $10 \mathrm{~mL}$ of $1 \mathrm{M} \mathrm{HCl}$. The reaction container was then transferred to a shaking bed (400 rpm, $20^{\circ} \mathrm{C}$ ), sampled after a certain time. The sample was centrifuged immediately at $13000 \mathrm{rpm}$ for $6 \mathrm{~min}$. The $\mathrm{Fe}$ content of the supernatant was detected via Inductively coupled plasma source mass spectrometer (ICP-MS). Part of the precipitate was redispersed in ethanol for TEM characterization and the remains was dried $\left(100{ }^{\circ} \mathrm{C}, 3 \mathrm{~h}\right.$, in an oven) for magnetism analysis. $2.5 \mathrm{~mL}$ of the suspension of $\alpha-\mathrm{Fe}_{2} \mathrm{O}_{3} @ \mathrm{SiO}_{2}$ (with different sol-gel reaction time) was centrifuged at $11000 \mathrm{rpm}$ for $10 \mathrm{~min}$. The supernatant was discarded and the precipitate was redispersed in $15 \mathrm{~mL}$ of $8.33 \mathrm{M} \mathrm{HCl}$. The reaction container was then transferred to a shaking bed $(400 \mathrm{rpm}$, $30{ }^{\circ} \mathrm{C}$ ), sampled after $1.5 \mathrm{~h}$. The sample was centrifuged immediately at $13000 \mathrm{rpm}$ for $6 \mathrm{~min}$. The supernatant was kept for content analysis of Fe via ICP-MS. The precipitation was redispersed in ethanol for TEM characterization.

\subsection{Cycling stability of $\mathrm{Fe}_{3} \mathrm{O}_{4}$ in adsorption of $\mathrm{Cu}^{2+}$}

The $\mathrm{Fe}_{3} \mathrm{O}_{4} @ \mathrm{SiO}_{2}$ particles were first functionalized with amino groups according to a reported recipe. ${ }^{39} \mathrm{~N}^{1}$-(3-Trimethoxysilylpropyl) diethylenetriamine $(0.5 \mathrm{~mL})$ and $N, N$-diisopropylethylamine $(0.1 \mathrm{~mL})$ were added to the mixture of $\mathrm{Fe}_{3} \mathrm{O}_{4} @ \mathrm{SiO}_{2}$ nanoparticles $(100 \mathrm{mg})$ and ethanol $(40 \mathrm{~mL})$. After stirring for $12 \mathrm{~h}$, the amino-modified nanoparticles were collected by centrifugation, cleaned with ethanol for several times, and dispersed in water. The cycling stability of $\mathrm{Fe}_{3} \mathrm{O}_{4}$ cores in the adsorption of $\mathrm{Cu}^{2+}$ was then tested. In a typical adsorptiondesorption cycle, $100 \mathrm{mg}$ of the amino-modified particles were mixed with $5 \mathrm{~mL}$ of aqueous $\mathrm{Cu}^{2+}$ solution $(0.005 \mathrm{M}, \mathrm{pH}=5)$, followed by magnetic stirring for $1.5 \mathrm{~h}$. After the adsorption, the magnetic particles were collected from the dispersion through magnetic separation. For the desorption of $\mathrm{Cu}^{2+}$, the recovered particles were then redispersed in $5 \mathrm{~mL}$ of $1 \mathrm{M} \mathrm{HCl}$, followed by magnetic stirring for $1.5 \mathrm{~h}$. Finally, the magnetic particles were collected through magnetic separation and cleaned with water to removes all copper ions and regenerate the adsorption sites. 


\section{Results and discussion}

Stöber method has been proven as an effective route to coat nanoparticles with silica shells. ${ }^{40,41}$ The sol-gel process involves the hydrolysis and condensation of a silane precursor (e.g. tetraethyl orthosilicate). ${ }^{42}$ Base catalysts (e.g. ammonium hydroxide) will accelerate the hydrolysis of the $\mathrm{Si}-\mathrm{OR}(\mathrm{R}=$ $\mathrm{CH}_{2} \mathrm{CH}_{3}$ for TEOS) groups to form silanol groups ( $\left.\mathrm{Si}-\mathrm{OH}\right)$. The further condensation of these silanol bonds will lead to the formation of $\mathrm{Si}-\mathrm{O}-\mathrm{Si}$ groups. However, the hydrolysis and condensation are imperfect, and unhydrolysed Si-OR and uncondensed $\mathrm{Si}-\mathrm{OH}$ groups exist inside newly formed silica shells. $^{43-45}$ Therefore, sol-gel silica colloids contain three functional groups: $\mathrm{Si}-\mathrm{O}-\mathrm{Si}, \mathrm{Si}-\mathrm{OH}$ and $\mathrm{Si}-\mathrm{OR}$. The amounts of $\mathrm{Si}-\mathrm{OR}$ groups and $\mathrm{Si}-\mathrm{O}-\mathrm{Si}$ groups determine the hydrolysis and condensation degrees, respectively. As the sol-gel reaction time (aging time) prolongs, the hydrolysis and condensation degrees (or aging degree) increase for silica shells. ${ }^{41}$ Our hypothesis is that the aging degree of silica shells may influence the ionic permeability and, thereby, protective ability.

To verify our hypothesis, an acid etching experiment was conducted on $\mathrm{Fe}_{3} \mathrm{O}_{4} @ \mathrm{SiO}_{2}$ nanoparticles to investigate the relationship between the aging time and the permeability of silica shells. $\mathrm{Fe}_{3} \mathrm{O}_{4}$ CNCs particles with an average diameter of $113 \mathrm{~nm}$ were prepared and encapsulated with a thin layer of solgel silica. Fig. 1a shows the transmission electron microscopy (TEM) image of the $\mathrm{Fe}_{3} \mathrm{O}_{4}$ particles, denoted as CNC. We also prepared two $\mathrm{Fe}_{3} \mathrm{O}_{4} @ \mathrm{SiO}_{2}$ samples with the sol-gel reaction time of 2 hours and 7 hours (denoted as $S_{2} h$ and $S_{7} h$ ), respectively. As shown in Fig. 1b and c, both samples have the same average shell thickness of $20 \mathrm{~nm}$. Thus, the influence of the shell thickness on the permeability can be neglected.

The same amount of CNCs, $\mathrm{S}_{2} \mathrm{~h}$ and $\mathrm{S}_{7 \mathrm{~h}}$ were etched by $\mathrm{HCl}$ (1 M) for 6 hours. The samples were centrifuged immediately after the etching. Fig. 1d shows the digital photos of the supernatants of the etched samples (denoted as $\mathrm{CNC}_{6 \mathrm{~h}}, \mathrm{~S}_{2 \mathrm{~h}-6 \mathrm{~h}}$, and $\mathrm{S}_{7} \mathrm{~h}-6 \mathrm{~h}$, corresponding to the original samples CNCs, $\mathrm{S}_{2} \mathrm{~h}$ and $\mathrm{S}_{7} \mathrm{~h}$, respectively). The etching of $\mathrm{Fe}_{3} \mathrm{O}_{4}$ was directly evidenced by the yellow colour of the supernatants. The supernatant of $\mathrm{CNC}_{6 \mathrm{~h}}$ appeared the darkest while the colour is the

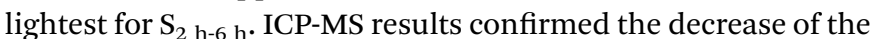
Fe content in the supernatants from $\mathrm{CNC}_{6 \mathrm{~h}}$ to $\mathrm{S}_{7 \mathrm{~h}-6 \mathrm{~h}}$, and then to $S_{2}$ h-6 h (Fig. S1†). These results suggest the etching rate of $\mathrm{Fe}_{3} \mathrm{O}_{4}$ is the fastest for CNCs without the silica protection. More importantly, the etching rate increased from $S_{2}$ h-6 h to $S_{7} h-6 h$, suggesting the shell permeability was different for the two samples. Since the two samples were made of the same CNCs cores with the same thickness of silica shells, it is most likely that the difference in the permeability could be attributed to the aging degree of silica shells.

Fourier transform infrared spectroscopy (FT-IR) was used to investigate the aging degrees of silica shells in $S_{2}$ h and $S_{7} h$. Fig. 2a and b depicts the normalized FT-IR spectra of sample $\mathrm{S}_{2}$ $\mathrm{h}$ and $\mathrm{S}_{7 \mathrm{~h}}$, respectively. The difference in the hydrolysis and condensation degrees between the two samples was revealed from the peak intensity at $2980 \mathrm{~cm}^{-1}$ and $1050 \mathrm{~cm}^{-1}$, which

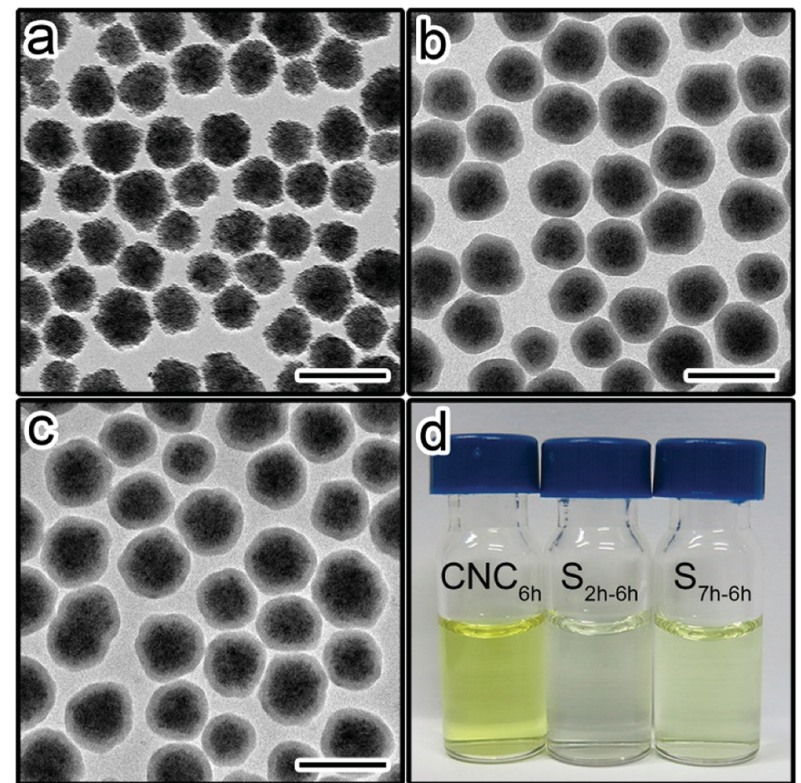

Fig. 1 TEM image of (a) $\mathrm{Fe}_{3} \mathrm{O}_{4} \mathrm{CNCs}$, (b) $\mathrm{CNCs} \mathrm{aSiO}_{2}$ particles with the sol-gel reaction time of 2 hours (sample $\mathrm{S}_{2}$ h), and (c) $\mathrm{CNCs} \mathrm{CSiO}_{2}$ particles with the sol-gel reaction time of 7 hours (sample $S_{7}$ h). Scale bars are $200 \mathrm{~nm}$. (d) Photograph of the supernatants of different etched samples.

could be assigned to the $\mathrm{Si}-\mathrm{O}-\mathrm{R}$ and $\mathrm{Si}-\mathrm{O}-\mathrm{Si}$ groups, respectively. ${ }^{46,47}$ To better compare their aging degrees, we performed a quantitative calculation similar to our previous study. ${ }^{41}$ The peak area ratio of the Si-O-R group $\left(2980 \mathrm{~cm}^{-1}\right)$ to the sum of $\mathrm{Si}-\mathrm{O}-\mathrm{Si}\left(1050 \mathrm{~cm}^{-1}\right)$ and $\mathrm{Si}-\mathrm{OH}\left(960 \mathrm{~cm}^{-1}\right)$ groups, $\mathrm{R}_{1}$, was used to compare the relative hydrolysis degree. The peak area ratio of the sum of $\mathrm{Si}-\mathrm{O}-\mathrm{R}$ and $\mathrm{Si}-\mathrm{OH}$ groups to the $\mathrm{Si}-\mathrm{O}-\mathrm{Si}$ group, $\mathrm{R}_{2}$, was used to compare the relative condensation degree. The values of $R_{1}$ and $R_{2}$ of the two samples were listed in Table 1 . Both $R_{1}$ and $R_{2}$ decreased from $S_{2}$ to $S_{7 h}$, confirming a higher aging degree for $\mathrm{S}_{7 \mathrm{~h}}$ with a longer sol-gel reaction time. ${ }^{41}$ These results suggest that the permeability of silica shells increases with the aging degree, which seems controversial to the common impression that more condensed gels are less permeable.

To thoroughly investigate the dependence of permeability on the aging degree of silica shells, we further prepared a set of $\mathrm{Fe}_{3} \mathrm{O}_{4} @ \mathrm{SiO}_{2}$ particles with similar thicknesses but different aging degrees (Fig. 3). The sol-gel reaction time of these
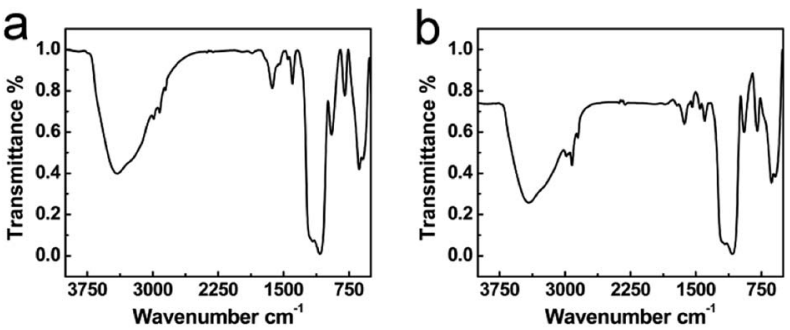

Fig. 2 Normalized FTIR spectra of (a) $S_{2} h$ and (b) $S_{7} h$. 
Table 1 The comparison of the IR peak areas corresponding to different functional groups for different samples

\begin{tabular}{llll}
\hline Sample & $t^{a}(\mathrm{~h})$ & $\mathrm{R}_{1}{ }^{b}$ & $\mathrm{R}_{2}{ }^{c}$ \\
\hline $\mathrm{S}_{2 \mathrm{~h}}$ & 2 & 0.3678 & 0.5003 \\
$\mathrm{~S}_{7 \mathrm{~h}}$ & 7 & 0.2548 & 0.3094
\end{tabular}

${ }^{a}$ The initial sol-gel reaction time for silica coating. ${ }^{b}$ The peak area ratio of the $\mathrm{Si}-\mathrm{O}-\mathrm{R}$ group $\left(2980 \mathrm{~cm}^{-1}\right)$ to the sum of $\mathrm{Si}-\mathrm{O}-\mathrm{Si}\left(1050 \mathrm{~cm}^{-1}\right)$ and $\mathrm{Si}-\mathrm{OH}\left(960 \mathrm{~cm}^{-1}\right)$ groups. The lower of this ratio, the higher the hydrolysis degree. ${ }^{c}$ The peak area ratio of the sum of $\mathrm{Si}-\mathrm{O}-\mathrm{R}$ and $\mathrm{Si}-$ $\mathrm{OH}$ groups to the $\mathrm{Si}-\mathrm{O}-\mathrm{Si}$ group. The lower of this ratio, the higher the condensation degree.

samples (denoted as $\mathrm{S}_{1 \mathrm{~h}}, \mathrm{~S}_{3 \mathrm{~h}}, \mathrm{~S}_{6 \mathrm{~h}}, \mathrm{~S}_{12 \mathrm{~h}}$, and $\mathrm{S}_{24 \mathrm{~h}}$, respectively) was varied between 1 hour, 3 hours, 6 hours, 12 hours, and 24 hours. As the sol-gel reaction time prolongs, the aging degree increases continuously from $\mathrm{S}_{1} \mathrm{~h}$ to $\mathrm{S}_{24} \mathrm{~h}^{41}$ The core-shell structure remains intact regardless of the aging time (Fig. 3a-e). As shown in Fig. 3f, the shell thickness was almost the same between this set of samples, which is beneficial for investigating the effect of aging degree on the permeability of silica shells.

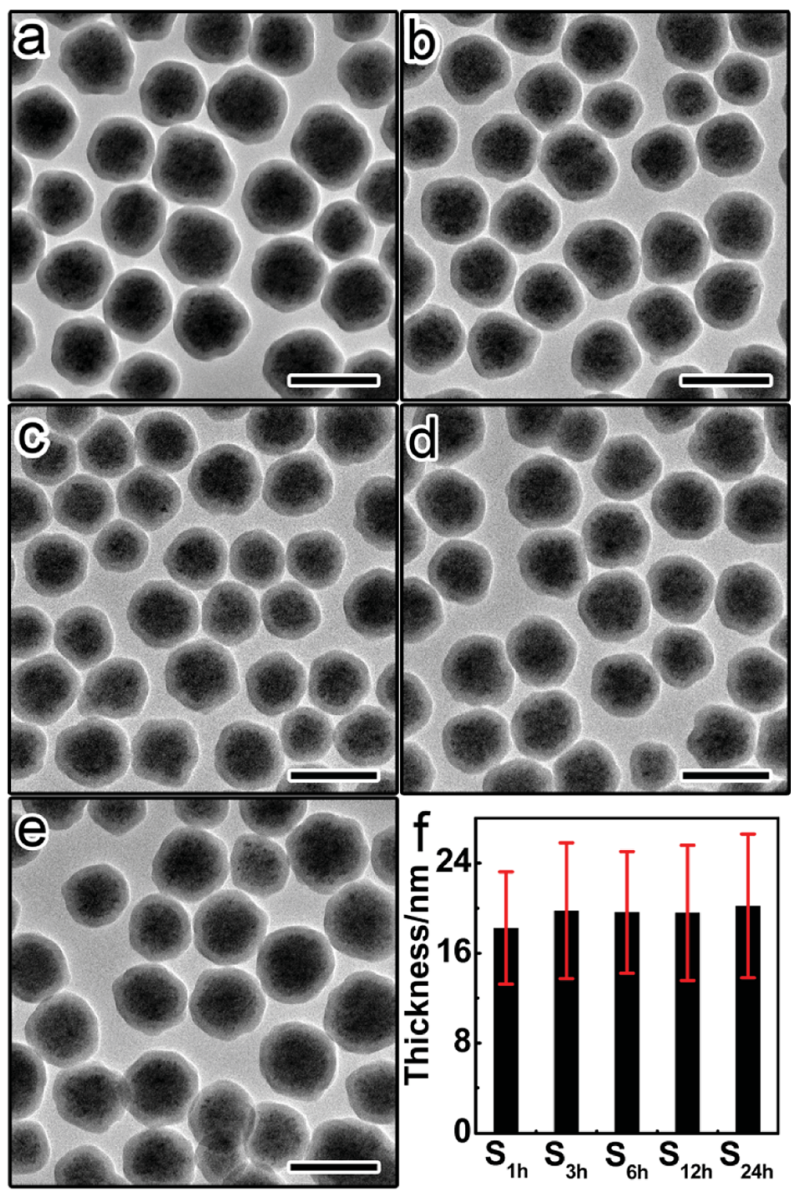

Fig. 3 TEM image of $\mathrm{CNCs} \mathrm{CSiO}_{2}$ particles with the sol-gel reaction time of (a) 1 hour (sample $S_{1}$ h), (b) 3 hours (sample $S_{3}$ h), (d) 6 hours (sample $S_{6}$ h), (d) 12 hours (sample $S_{12}$ h), and (e) 24 hours (sample $S_{24}$ h). Scale bars are $200 \mathrm{~nm}$. (f) Distributions of the shell thickness for different samples.
This set of five samples were etched by $\mathrm{HCl}(1 \mathrm{M})$ for 3 hours, followed by immediate centrifugation. Fig. 4a-e shows the TEM images of the precipitates from different etched samples. The amount of residual $\mathrm{Fe}_{3} \mathrm{O}_{4}$ in the precipitates was found to continuously decrease from $S_{1 h-3}$ to $S_{24}$ h-3 h, suggesting the increase of the etching rate with higher aging degrees of silica shells. This trend was further confirmed by the gradual increase of the Fe content in the supernatants from $S_{1 h-3}$ to $S_{24 h-3 h}$ (Fig. 4f). These results prove that silica shells become more permeable to $\mathrm{HCl}$ and less protective when increasing the aging degree.

Such discrepancy in the protective ability was even more significant if we extended the etching time to 10 hours. A similar trend in the amount of remaining $\mathrm{Fe}_{3} \mathrm{O}_{4}$ was found in the etched samples (Fig. S2a-e $\dagger$ ). The difference in the Fe content of the supernatant is much more pronounced between $S_{1 \mathrm{~h}-10 \mathrm{~h}}$ and any of the other four etched samples (Fig. S2f $\dagger$ ). These results further demonstrate that the protective ability of silica shells is strongly dependent on their aging degrees.

The higher etching rate of $\mathrm{Fe}_{3} \mathrm{O}_{4}$ for samples with more aged silica shells was also evidenced by the magnetization measurements. Fig. 5a shows the hysteresis loops of the above-

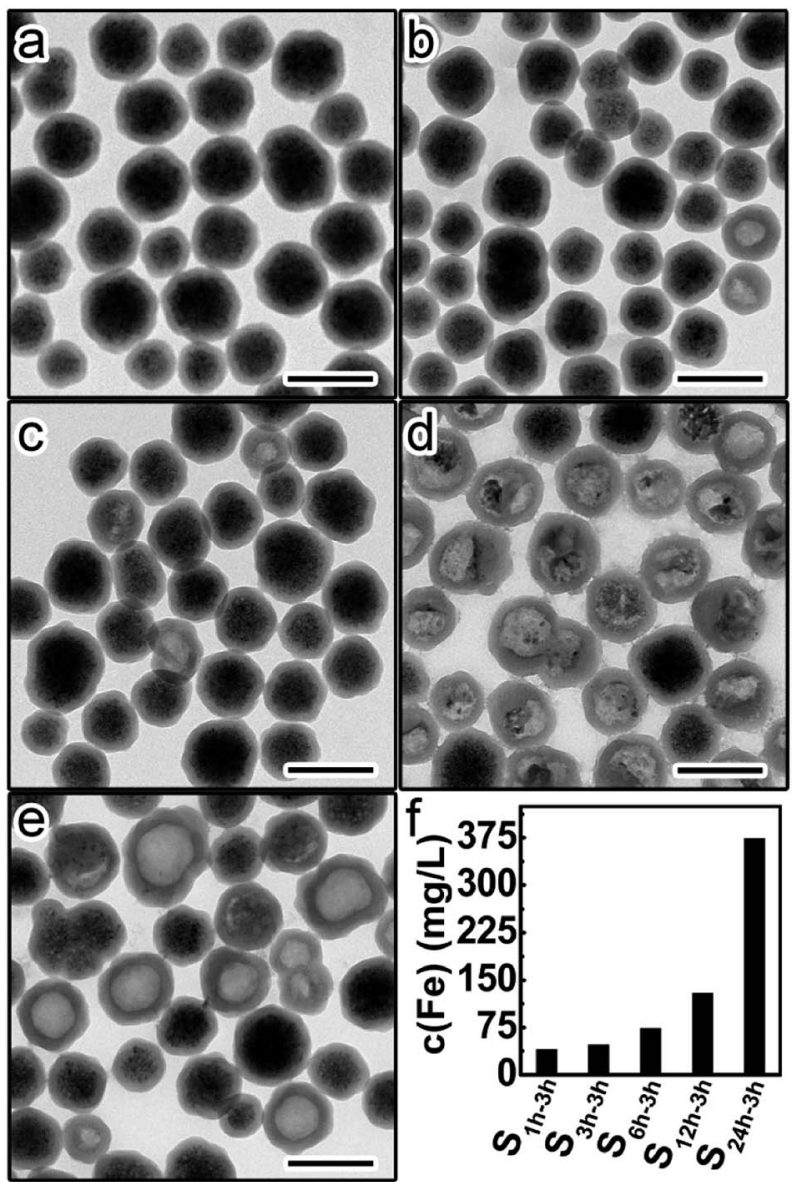

Fig. 4 TEM images of the precipitates from different etched samples: (a) $S_{1 h-3 h}$, (b) $S_{3 h-3 h}$, (c) $S_{6 h-3 h}$ (d) $S_{12 h-3 h}$, and (e) $S_{24 h-3 h}$. Scale bars are $200 \mathrm{~nm}$. (f) Fe contents in the supernatants of different etched samples. 
mentioned five samples before etching. All samples were superparamagnetic at room temperature with negligible coercive forces $\left(H_{\mathrm{c}}\right)$ and remanent magnetizations $\left(M_{\mathrm{r}}\right)$. The saturation magnetizations were almost the same for this set of five samples. The slight difference resulted from the small variance in the shell thickness. After the 10 hour etching, we observed an obvious and continuous drop in the saturation magnetization $\left(M_{\mathrm{S}}\right)$ from $\mathrm{S}_{1 \mathrm{~h}-10 \mathrm{~h}}$ to $\mathrm{S}_{24 \mathrm{~h}-10 \mathrm{~h}}$ (Fig. $5 \mathrm{~b}$ and $\mathrm{c}$ ). This trend is consistent with the fact that more amounts of $\mathrm{Fe}_{3} \mathrm{O}_{4}$ were etched away for samples with more aged silica shells.
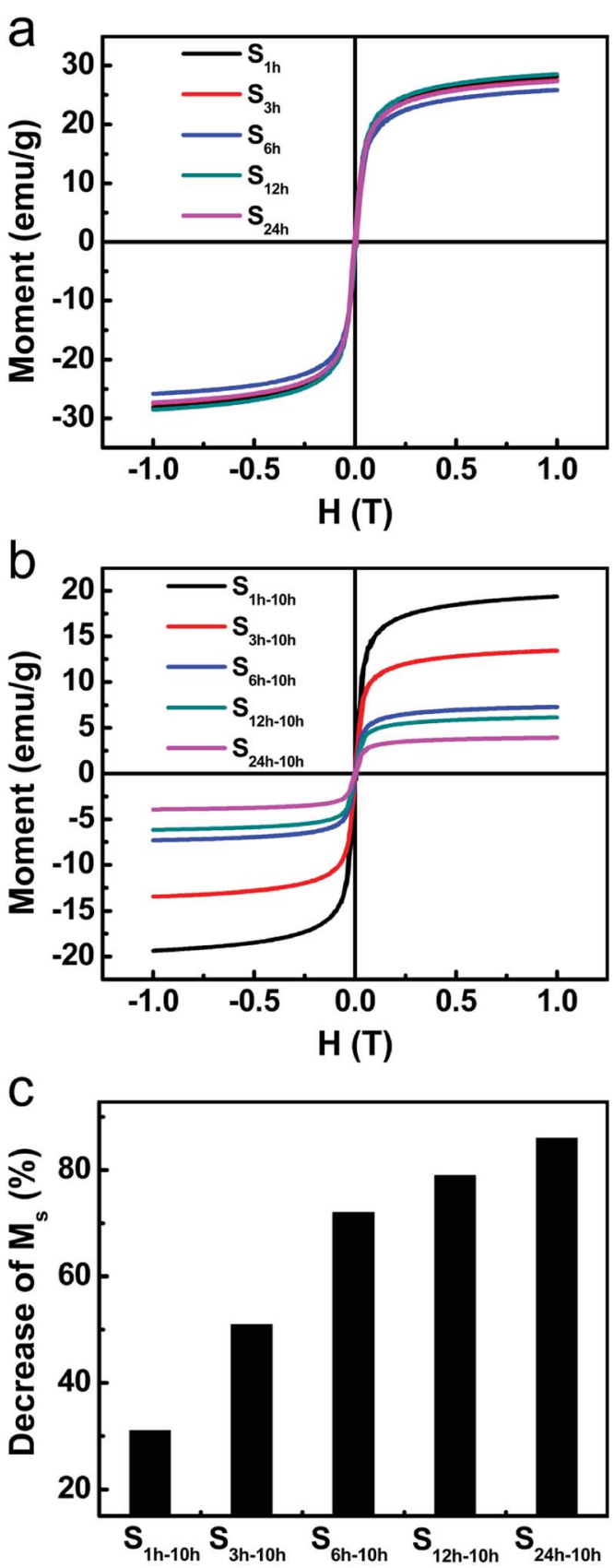

Fig. 5 (a) The magnetic hysteresis loops of $S_{1 h}, S_{3 h}, S_{6}, S_{12} h$, and $S_{24}$ $\mathrm{h}$ at room temperature. (b) The magnetic hysteresis loops of precipitates of $S_{1 h-10 h}, S_{3 h-10 h}, S_{6 h-10 h}, S_{12 h-10 h}$ and $S_{24 h-10 h}$ at room temperature. (c) Relative drop of the saturation magnetization after etching.
As shown above, we found that silica shells with higher aging degrees are more permeable to ions. One plausible explanation for this observed trend is that the wettability of silica shells is affected by their aging degrees. Compared with the $\mathrm{Si}-\mathrm{OC}_{2} \mathrm{H}_{5}$ group, the $\mathrm{Si}-\mathrm{OH}$ group exhibits stronger hydrogen bonding ability with water and is, thus, more hydrophilic. The presence of more hydrophobic $\mathrm{Si}-\mathrm{OC}_{2} \mathrm{H}_{5}$ groups in less aged silica shells, as confirmed by FT-IR studies, hinders the transportation of water molecules and hydrated ions (such as $\mathrm{H}^{+}, \mathrm{Fe}^{2+}$ and $\mathrm{Fe}^{3+}$ ). In contrast, the ionic permeability is greatly improved for more aged silica shells with a lower number of $\mathrm{Si}-\mathrm{OC}_{2} \mathrm{H}_{5}$ groups but a higher concentration of hydrophilic $\mathrm{Si}-\mathrm{OH}$ groups. One may propose another possibility that the aging process may create pores that serve as the ionic channels. ${ }^{32}$ However, no micropores or mesopores were found in either $S_{1 h}$ or $S_{24}$ from the Brunauer-Emmett-Teller (BET) measurements (Fig. S3†). It is most likely that the contrast in the wettability accounts for the observed trend. While further studies are necessary to fully elucidate the mechanism, the present study clearly demonstrates that the protective ability of silica shells can be chemically tuned by simply varying the aging degree.

Besides $\mathrm{Fe}_{3} \mathrm{O}_{4} \mathrm{CNCs}$, we further studied the etching of silicacoated $\alpha-\mathrm{Fe}_{2} \mathrm{O}_{3}$ nanoparticles in an attempt to justify the versatility of the aging degree effect. Ellipsoidal $\alpha-\mathrm{Fe}_{2} \mathrm{O}_{3}$ nanoparticles were coated with a thin layer of silica to prepare two $\alpha$ $\mathrm{Fe}_{2} \mathrm{O}_{3} @ \mathrm{SiO}_{2}$ samples with the same shell thickness (Fig. S4a and $\mathrm{b}_{\dagger} \dagger$ ). The sol-gel reaction time was varied between 1 hour and 24 hours. After being treated in $\mathrm{HCl}$ under the same conditions, more $\alpha-\mathrm{Fe}_{2} \mathrm{O}_{3}$ were etched away for the 24 hour sample (Fig. S4c-f $\dagger$ ). These results again suggest that silica shells with higher aging degree exhibit higher ionic permeability regardless of the core composition and particle shape.

Thanks to the improved understanding of the aging degree effect, it is now possible to rationally tune the protective ability of silica shells without changing the thickness, e.g. simply by adjusting the sol-gel reaction time. Finally, we demonstrate the use of thin but low-permeability shells to improve the cycling stability of iron oxide nanoparticles when used in the removal of metal ions. Notably, the desorption of metal ions is usually carried out under strongly acidic conditions (e.g. $1 \mathrm{M} \mathrm{HCl}$ ). This raises the concern on the etching of iron oxide and the decrease of the recycling efficiency of nanoparticles through magnetic separation. Two samples $S_{1}$ h and $S_{24}$ were functionalized with amino groups. The modified samples (denoted as $\mathrm{S}_{1 \mathrm{~h}}-\mathrm{NH}_{2}$ and $\mathrm{S}_{24 \mathrm{~h}}-\mathrm{NH}_{2}$, respectively) were then used as the adsorbents in the removal of $\mathrm{Cu}^{2+}$. Magnetic separation was used for the recovering and cleaning of the particles. In the first cycle, both magnetic nanoparticles could be quickly separated from the dispersion within 60 seconds (Fig. $6 \mathrm{a}$ and $\mathrm{b}$ inset). TEM images revealed that the core-shell structures remained intact after the first cycle (Fig. 6a and b). However, the difference between the two samples appeared gradually during the cycling tests. For example, in the $8^{\text {th }}$ cycle, no obvious drop in the separation efficiency was found for $\mathrm{S}_{1} \mathrm{~h}^{-} \mathrm{NH}_{2}$ (Fig. 6c inset). This is consistent with the preservation of the $\mathrm{Fe}_{3} \mathrm{O}_{4}$ cores after 8 cycles (Fig. 6c). In contrast, severe etching of $\mathrm{Fe}_{3} \mathrm{O}_{4}$ occurred for $\mathrm{S}_{24} \mathrm{~h}^{-}$ $\mathrm{NH}_{2}$ (Fig. 6d). Consequently, the magnetic separation process 


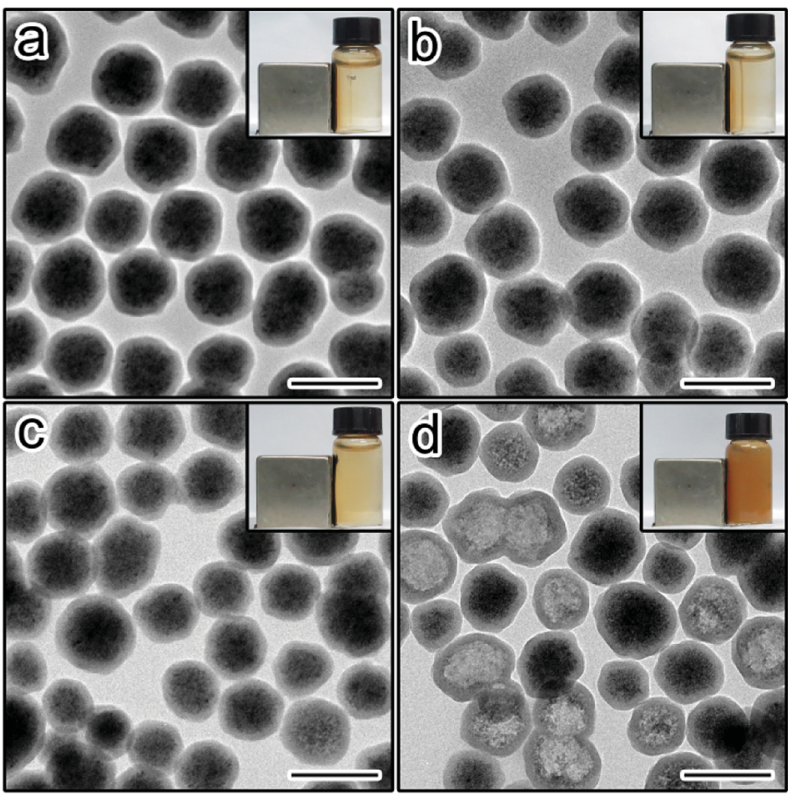

Fig. 6 TEM image of (a) $\mathrm{S}_{1 \mathrm{~h}}-\mathrm{NH}_{2}$, (b) $\mathrm{S}_{24} \mathrm{~h}-\mathrm{NH}_{2}$, (c) $\mathrm{S}_{1 \mathrm{~h}}-\mathrm{NH}_{2}$ after 8 cycles of $\mathrm{Cu}^{2+}$ removal experiments, and (d) $\mathrm{S}_{2} 4 \mathrm{~h}-\mathrm{NH}_{2}$ after 8 cycles of $\mathrm{Cu}^{2+}$ removal experiments. Scale bars are $200 \mathrm{~nm}$. The inset in each image shows the corresponding samples dispersed in water after magnetic separation for $60 \mathrm{~s}$.

became much slower, leading to unwanted losses of adsorbents (Fig. 6d inset). It is believed that these thin but low-permeability silica shells can also stabilize nanoparticles with different compositions and functionalities, facilitating their applications in different areas.

\section{Conclusions}

In summary, we have systematically studied the effect of the aging degree on the ionic permeability of silica shells. Contradictory to common impressions, we found that the ionic permeability of silica shells increased rather than decreased with the increasing aging degree. This trend may be explained by the chemical nature of the silica shell that affects the wettability, and thereby the transportation of water molecules and hydrated ions. More importantly, our study provides a feasible and effective way for chemically improving the protective ability of silica shells by simply controlling the solgel reaction time, which does not rely on the increase of the shell thickness that usually scarifies the performance of nanoparticles. Such insights into the protective ability of sol-gel derived silica would facilitate the practical implementation of silica-coated nanoparticles in the field of environmental remediation, demonstrated by a model experiment for repetitive $\mathrm{Cu}$ ion removal from water, as well as other potential applications in photonics, catalysis, and biomedicine.

\section{Conflicts of interest}

There are no conflicts to declare.

\section{Acknowledgements}

We acknowledge the support from the Natural Science Foundation of Jiangsu Province (BK20160309, 1601042C), the National Natural Science Foundation of China (Grant No. 51802208, 51373188, 21401135, 51772200), the China Postdoctoral Science Foundation (2017M611893), 111 project, the Collaborative Innovation Centre of Suzhou Nano Science \& Technology, and the Priority Academic Program Development of Jiangsu Higher Education Institutions (PAPD) and Qing Lan Project.

\section{Notes and references}

1 X. Xia, Y. Wang, A. Ruditskiy and Y. Xia, Adv. Mater., 2013, 25, 6313-6333.

2 M. Auffan, J. Rose, M. R. Wiesner and J.-Y. Bottero, Environ. Pollut., 2009, 157, 1127-1133.

3 G. D. Moon, S. Ko, Y. Min, J. Zeng, Y. Xia and U. Jeong, Nano Today, 2011, 6, 186-203.

4 C. Levard, E. M. Hotze, G. V. Lowry and G. E. Brown, Environ. Sci. Technol., 2012, 46, 6900-6914.

5 J. B. Rivest and P. K. Jain, Chem. Soc. Rev., 2013, 42, 89-96. 6 L. Xu, H.-W. Liang, H.-H. Li, K. Wang, Y. Yang, L.-T. Song, X. Wang and S.-H. Yu, Nano Res., 2014, 8, 1081-1097.

7 L. Xu, H.-W. Liang, Y. Yang and S.-H. Yu, Chem. Rev., 2018, 118, 3209-3250.

8 Q. Zhang, W. Wang, J. Goebl and Y. Yin, Nano Today, 2009, 4, 494-507.

9 G. Jianping and Y. Yadong, Adv. Mater., 2008, 20, 3485-3491.

10 J. Ge, L. He, J. Goebl and Y. Yin, J. Am. Chem. Soc., 2009, 131, 3484-3486.

11 L. Tang, B. Han, K. Persson, C. Friesen, T. He, K. Sieradzki and G. Ceder, J. Am. Chem. Soc., 2010, 132, 596-600.

12 L. Tang, X. Li, R. C. Cammarata, C. Friesen and K. Sieradzki, J. Am. Chem. Soc., 2010, 132, 11722-11726.

13 Y. Zhang, M. Wang, Y.-g. Zheng, H. Tan, B. Y.-w. Hsu, Z.-c. Yang, S. Y. Wong, A. Y.-c. Chang, M. Choolani, X. Li and J. Wang, Chem. Mater., 2013, 25, 2976-2985.

14 Y. Bai, C. Gao and Y. Yin, Nanoscale, 2017, 9, 14875-14880.

15 S. H. Joo, J. Y. Park, C.-K. Tsung, Y. Yamada, P. Yang and G. A. Somorjai, Nat. Mater., 2008, 8, 126.

16 R. Hao, R. Xing, Z. Xu, Y. Hou, S. Gao and S. Sun, Adv. Mater., 2010, 22, 2729-2742.

17 Y. Hu, L. He and Y. Yin, Small, 2012, 8, 3795-3799.

18 F. Ge, M.-M. Li, H. Ye and B.-X. Zhao, J. Hazard. Mater., 2012, 211-212, 366-372.

19 S. A. Elfeky, S. E. Mahmoud and A. F. Youssef, J. Adv. Res., 2017, 8, 435-443.

20 K. Zargoosh, H. Abedini, A. Abdolmaleki and M. R. Molavian, Ind. Eng. Chem. Res., 2013, 52, 14944-14954.

21 S. Bao, K. Li, P. Ning, J. Peng, X. Jin and L. Tang, Appl. Surf. Sci., 2017, 393, 457-466.

22 J. Wang, S. Zheng, Y. Shao, J. Liu, Z. Xu and D. Zhu, J. Colloid Interface Sci., 2010, 349, 293-299.

23 X. Xin, Q. Wei, J. Yang, L. Yan, R. Feng, G. Chen, B. Du and H. Li, Chem. Eng. J., 2012, 184, 132-140. 
24 J. Zhang, S. Zhai, S. Li, Z. Xiao, Y. Song, Q. An and G. Tian, Chem. Eng. J., 2013, 215-216, 461-471.

25 C. Shan, Z. Ma, M. Tong and J. Ni, Water Res., 2015, 69, 252260.

26 I. Lee, M. A. Albiter, Q. Zhang, J. Ge, Y. Yin and F. Zaera, Phys. Chem. Chem. Phys., 2011, 13, 2449-2456.

27 I. Lee, Q. Zhang, J. Ge, Y. Yin and F. Zaera, Nano Res., 2011, 4, 115-123.

28 S. A. Jadhav, R. Nisticò, G. Magnacca and D. Scalarone, $R S C$ Adv., 2018, 8, 1246-1254.

29 S. L. C. Pinho, G. A. Pereira, P. Voisin, J. Kassem, V. Bouchaud, L. Etienne, J. A. Peters, L. Carlos, S. Mornet, C. F. G. C. Geraldes, J. Rocha and M.-H. Delville, ACS Nano, 2010, 4, 5339-5349.

30 H. M. Joshi, M. De, F. Richter, J. He, P. V. Prasad and V. P. Dravid, J. Nanopart. Res., 2013, 15, 1448.

31 J. Kang, Y. Li, Y. Chen, A. Wang, B. Yue, Y. Qu, Y. Zhao and H. Chu, Mater. Res. Bull., 2015, 71, 116-121.

32 T. Zhao, N. Goswami, J. Li, Q. Yao, Y. Zhang, J. Wang, D. Zhao and J. Xie, Small, 2016, 12, 6537-6541.

33 C. Ma, C. Li, N. He, F. Wang, N. Ma, L. Zhang, Z. Lu, Z. Ali, Z. Xi, X. Li, G. Liang, H. Liu, Y. Deng, L. Xu and Z. Wang, J. Biomed. Nanotechnol., 2012, 8, 1000-1005.

34 B. Wang, X. He, Z. Zhang, Y. Zhao and W. Feng, Acc. Chem. Res., 2013, 46, 761-769.

35 C. Yu, C. Hangrong and S. Jianlin, Adv. Mater., 2013, 25, 3144-3176.
36 J. Gao, X. Ran, C. Shi, H. Cheng, T. Cheng and Y. Su, Nanoscale, 2013, 5, 7026-7033.

37 T. Sugimoto, Y. Wang, H. Itoh and A. Muramatsu, Colloids Surf., A, 1998, 134, 265-279.

38 P. Yang, H. Li, S. Zhang, L. Chen, H. Zhou, R. Tang, T. Zhou, F. Bao, Q. Zhang, L. He and X. Zhang, Nanoscale, 2016, 8, 19036-19042.

39 M. Cheng, Z. Wang, Q. Lv, C. Li, S. Sun and S. Hu, J. Hazard. Mater., 2018, 341, 198-206.

40 S. Zhang, C. Li, Y. Yu, Z. Zhu, W. Zhang, R. Tang, W. Sun, W. Xie, Y. Li, J. Yu, L. He and X. Zhang, J. Mater. Chem. C, 2018, 6, 5528-5535.

41 Z. Zhu, S. Zhang, C. Li, J. Zhang, J. Yu, X. Du, L. He and X. Zhang, Phys. Chem. Chem. Phys., 2018, 20, 1440-1446.

42 W. Stöber, A. Fink and E. Bohn, J. Colloid Interface Sci., 1968, 26, 62-69.

43 Y. Hu, Q. Zhang, J. Goebl, T. Zhang and Y. Yin, Phys. Chem. Chem. Phys., 2010, 12, 11836-11842.

44 Y. J. Wong, L. Zhu, W. S. Teo, Y. W. Tan, Y. Yang, C. Wang and H. Chen, J. Am. Chem. Soc., 2011, 133, 11422-11425.

45 G. B. Alexander, W. M. Heston and R. K. Iler, J. Phys. Chem., 1954, 58, 453-455.

46 G. H. Du, Z. L. Liu, X. Xia, Q. Chu and S. M. Zhang, J. Sol-Gel Sci. Technol., 2006, 39, 285-291.

47 R. Al-Oweini and H. El-Rassy, J. Mol. Struct., 2009, 919, 140145. 